\title{
Metabolic Disposition of Dapsone in African Leprosy Patients*
}

\author{
JOHN H. PETERS, † G. ROSS GORDON, J. F. MURRAY, JR \\ Life Sciences Division, SRI International, \\ Menlo Park, California 94025, U.S.A. \\ and \\ WAYNE M. MEYERS $\ddagger$ \\ Institut Medical Evangelique, Kimpese, Zaire
}

\begin{abstract}
In a preliminary study (Study 1) of 20 African leprosy patients receiving various doses of dapsone (DDS), we found a distribution of capacities to acetylate DDS that suggested the polymorphism of acetylation observed in other populations. A more detailed investigation (Study 2) in a subsequent group of 21 patients using sulfamethazine (SMZ) as the primary drug for determining acetylator phenotype as well as DDS clearly demonstrated that African patients exhibit the polymorphism of acetylation of these drugs. As in other populations studied previously, plasma clearance rates of DDS as expressed by the half-time of disappearance were unrelated to acetylator phenotype. Clearance rates or acetylation capacities were also unrelated to age, sex, or body weight of the patients, or to the dose of DDS administered per week. In 5 patients who participated in both Studies 1 and 2, no consistent marked differences in acetylation of DDS or plasma clearance rates of DDS were noted even though the two studies were separated by 11 months. A positive linear relationship between the 4-h level of DDS after the last dose and total dose of DDS per week was observed.
\end{abstract}

\section{Introduction}

Dapsone (4,4'-diaminodiphenylsulfone, DDS) has been for over 30 years and continues to be the principal drug for leprosy chemotherapy (Sansarricq, 1977). The repository form of this drug, acedapsone $\left(4,4^{\prime}\right.$-diacetamidodiphenylsulfone, DADDS), has also been employed as an eff ective intermittent treatment for leprosy (Russell et al., 1975; Peters et al., 1977b).

In a continuation of our efforts to define the characteristics of various human populations for metabolizing DDS (Gelber et al., 1971; Peters et al., $1972,1975,1976 b, 1977 b$ ), we present in this paper the results of studies in African leprosy patients.

* Supported in part by the U.S.-Japan Cooperative Medical Science Program administered by the National Institute of Allergy and Infectious Diseases, National Institutes of Health, Bethesda, Maryland, U.S.A. (grant R22 AI-08214 and contract NIH 70-2283). A preliminary report of these studies was presented previously (Peters, 1972).

$\dagger$ Requests for reprints should be addressed to John H. Peters, Ph.D.

$\ddagger$ Present address: Armed Forces Institute of Pathology, Washington, D.C. 20306, U.S.A. 


\section{Materials and Methods}

The DDS used in these studies was in the form of 25- or 50-mg tablets (P.C.B., Brussels, Belgium) in which we previously found only minor sulf one contaminants (Gordon et al., 1975). The SMZ was a crystalline material (Lederle Laboratories, Pearl River, New York, U.S.A.). Serum or plasma concentrations of DDS and monacetyl DDS (MADDS) were measured routinely by a fluorometric procedure (Peters et al., 1970); in samples exhibiting levels near the limit of sensitivity of this method $(0.01 \mu \mathrm{g} / \mathrm{ml})$, we applied the more sensitive chromatographic-fluorometric technique of Murray et al. (1971). Plasma and urine concentrations of SMZ and $N$-acetyl SMZ (AcSMZ) were measured colorimetrically (Gelber et al., 1971).

Study 1 was a preliminary survey of levels of DDS and MADDS in samples of serum collected from patients receiving various therapeutic regimens of DDS.* It was undertaken without detailed plans regarding any other subsequent evaluations and interpretations. Sera were obtained at 8, 24 and $96 \mathrm{~h}$ from 5 patients receiving $25 \mathrm{mg}$ DDS, twice weekly; at 8,24 and $72 \mathrm{~h}$ from 10 patients receiving $25 \mathrm{mg}$ DDS, thrice weekly; and at 8,24 and $48 \mathrm{~h}$ from 5 patients receiving $50 \mathrm{mg}$ DDS, thrice weekly. From each patient, the last sampling of serum was taken immediately before the next dose of DDS. The serum samples were stored and shipped frozen over dry ice to the Menlo Park laboratories where analyses were performed within 8 weeks of the time of collection. We (Gelber et al., 1971; Peters et al., 1972) and others (Ellard et al., 1971) had found that DDS and MADDS were stable in serum or plasma stored frozen for up to 12 months.

Eleven months later, Study 2 was carried out wherein 21 patients were phenotyped for acetylator status (Peters et al., 1975) using an oral dose of 10 $\mathrm{mg} \mathrm{SMZ} / \mathrm{kg}$ after having been removed from their regular DDS regimens for 7 days. Following SMZ, urine was collected during 0 to $6 \mathrm{~h}$, and a single 6 -h heparinized plasma sample was taken from each patient. The patients were immediately returned to their DDS regimens. Five of these patients had been subjects in Study 1. All patients of Study 2 provided heparinized plasma at 4, $6,8,24$ and $48 \mathrm{~h}$ after DDS administration. Nine of the 21 patients were receiving $25 \mathrm{mg}$ DDS twice weekly; $8,25 \mathrm{mg}$ DDS thrice weekly; $2,50 \mathrm{mg}$ DDS twice weekly; and one each, $50 \mathrm{mg}$ DDS thrice weekly and five times weekly. All plasma and urine samples were frozen after collection and shipped frozen to the Menlo Park laboratories for analysis.

Percentage acetylation of DDS and SMZ was calculated from the fraction: acetylated drug divided by the total of parent and acetylated drug. In all computations, acetylated drug was expressed in parent drug equivalents. In studies with DDS, the mean percentage acetylation was the average of values obtained from all plasma samplings in each patient. Relationships between groups of data were examined by calculating linear regression equations and correlation coefficients $(r)$ to determine whether the slopes of the lines were significantly different from zero (Goldstein, 1964). Half-times of disappearance $\left(T_{\frac{1}{2}}\right)$ for

* We are indebted to Dr C. H. Binford, Armed Forces Institute of Pathology, Washington, D.C., for acting as intermediary in this preliminary study. 
TABLE 1

Results of Study 1

\begin{tabular}{|c|c|c|c|c|}
\hline \multirow{2}{*}{$\begin{array}{l}\text { Treatment } \\
\text { group }\end{array}$} & \multirow{2}{*}{$\begin{array}{c}\text { Study-patient } \\
\text { designation }\end{array}$} & \multirow{2}{*}{$\begin{array}{c}\% \text { Acetylation } \\
\text { of DDS } \\
\text { Mean } \pm \text { S.E. }\end{array}$} & \multicolumn{2}{|c|}{$T_{\frac{1}{2}}$ value* $_{(\mathrm{h})}^{*}$} \\
\hline & & & DDS & MADDS \\
\hline \multirow{5}{*}{$\begin{array}{l}25 \mathrm{mg} \text { DDS, } \\
2 \times \text { per week }\end{array}$} & $1-1$ & $19 \pm 2$ & 24 & 28 \\
\hline & $1-2$ & $19 \pm 2$ & 38 & 47 \\
\hline & $1-3$ & $23 \pm 2$ & 33 & 36 \\
\hline & $1-4$ & $18 \pm 1$ & 83 & 62 \\
\hline & $1-5$ & $27 \pm 1 \dagger$ & $-\dagger$ & $-\dagger$ \\
\hline \multirow{10}{*}{$\begin{array}{l}25 \mathrm{mg} \text { DDS } \\
3 \times \text { per week }\end{array}$} & $1-6$ & $45 \pm 1$ & 35 & 32 \\
\hline & $1-7$ & $42 \pm 2$ & 27 & 32 \\
\hline & $1-8$ & $15 \pm<1$ & 24 & 24 \\
\hline & $1-9$ & $13 \pm 1 \dagger$ & $-\dagger$ & $-\dagger$ \\
\hline & $1-10$ & $13 \pm 1$ & 26 & 30 \\
\hline & $1-11$ & $16 \pm 1$ & 28 & 34 \\
\hline & $1-12$ & $36 \pm<1$ & 41 & 37 \\
\hline & $1-13$ & $14 \pm<1$ & 56 & 48 \\
\hline & $1-14$ & $13 \pm<1$ & 38 & 48 \\
\hline & $1-15$ & $14 \pm 1$ & 61 & 49 \\
\hline \multirow{5}{*}{$\begin{array}{l}50 \text { mg DDS, } \\
3 \times \text { per week }\end{array}$} & $1-16$ & $34 \pm<1$ & 30 & 32 \\
\hline & $1-17$ & $14 \pm 1 \dagger$ & $-\dagger$ & $-\dagger$ \\
\hline & $1-18$ & $30 \pm<1$ & 18 & 16 \\
\hline & $1-19$ & $33 \pm 2$ & 22 & 27 \\
\hline & $1-20$ & $20 \pm<1$ & 16 & 18 \\
\hline
\end{tabular}

* $T_{\frac{1}{2}}$ values were calculated from regression equations of levels of DDS at 8 and $24 \mathrm{~h}$ and either 48,72 or $96 \mathrm{~h}$ following administration; $r$ values $\geqslant-0.95$.

† Only 2 specimens of serum were collected.

DDS and MADDS were calculated from the regression equations representing the logarithmic decay of the compounds with time. The Student $t$-test was used to determine the significance of differences between mean values (Goldstein, 1964).

\section{Results}

From the results of analyses of the sera of Study 1, we calculated the mean percentage acetylation of DDS and $T_{\frac{1}{2}}$ values of DDS and MADDS*. These are listed in Table 1, wherein the patients are grouped by dosage of DDS. Each patient exhibited nearly the same acetylation of DDS at the various times of sampling of serum as shown by the very small variations around the mean. From these results, we tentatively classified patients $5,6,7,12,16,18$ and 19 as rapid acetylators, and the other 13 patients as slow acetylators by assuming an antimode of between 23 and $27 \%$ acetylation. Within the various treatment groups of Table 1, we calculated that $20 \%$ of the low dosage group, $30 \%$ of the

* Raw data from these patients and those from patients of Study 2 are available on request from the senior author. 
TABLE 2

Results of Study 2

\begin{tabular}{|c|c|c|c|c|c|c|}
\hline \multirow{2}{*}{$\begin{array}{l}\text { Treatment } \\
\text { group }\end{array}$} & \multirow{2}{*}{$\begin{array}{l}\text { Study-patient } \\
\text { designation }\end{array}$} & \multicolumn{2}{|c|}{$\%$ Acetylation of SMZ* } & \multirow{2}{*}{$\begin{array}{c}\% \text { Acetylation of DDS } \\
\text { Mean } \pm \text { S.E. }{ }^{\dagger}\end{array}$} & \multicolumn{2}{|c|}{$\Gamma_{\frac{1}{2}}$ value $\neq$} \\
\hline & & Plasma & Urine & & DDS & MADDS \\
\hline $\begin{array}{l}25 \mathrm{mg} \text { DDS } \\
2 \times \text { per week }\end{array}$ & $\begin{array}{l}2-1 \\
2-02 \\
2-03 \\
2-04 \\
2-05 \\
2-8 \\
2-09 \\
2-010 \\
2-011\end{array}$ & $\begin{array}{l}16 \\
71 \\
68 \\
36 \\
24 \\
24 \\
24 \\
56 \\
33\end{array}$ & $\begin{array}{l}52 \\
88 \\
89 \\
60 \\
54 \\
53 \\
56 \\
91 \\
50\end{array}$ & $\begin{array}{l}10 \pm<1 \\
26 \pm<1 \\
32 \pm 2 \\
19 \pm<1 \\
13 \pm<1 \\
15 \pm<1 \\
12 \pm 1 \\
31 \pm 1 \\
16 \pm<1\end{array}$ & $\begin{array}{l}18 \\
25 \\
24 \\
24 \\
23 \\
18 \S \\
33 \\
32 \\
34\end{array}$ & $\begin{array}{l}20 \\
27 \\
31 \\
21 \\
22 \\
21 \S \\
54 \\
35 \\
39\end{array}$ \\
\hline $\begin{array}{l}25 \mathrm{mg} \text { DDS } \\
3 \times \text { per week }\end{array}$ & $\begin{array}{l}2-7 \\
2-012 \\
2-013 \\
2-014 \\
2-015 \\
2-017 \\
2-018 \\
2-019\end{array}$ & $\begin{array}{l}87 \\
38 \\
74 \\
73 \\
24 \\
23 \\
29 \\
32\end{array}$ & $\begin{array}{l}94 \\
70 \\
88 \\
88 \\
67 \\
59 \\
59 \\
64\end{array}$ & $\begin{array}{l}41 \pm 1 \\
21 \pm<1 \\
32 \pm<1 \\
31 \pm 1 \\
12 \pm 1 \\
19 \pm<1 \\
15 \pm<1 \\
15 \pm 1\end{array}$ & $\begin{array}{l}24 \\
22 \\
25 \\
36 \\
40 \\
33 \\
40 \\
29\end{array}$ & $\begin{array}{l}27 \\
23 \\
24 \\
36 \\
44 \\
33 \\
31 \\
26\end{array}$ \\
\hline $\begin{array}{l}50 \mathrm{mg} \text { DDS } \\
2 \times \text { per week }\end{array}$ & $\begin{array}{l}2-16 \\
2-020\end{array}$ & $\begin{array}{l}71 \\
27\end{array}$ & $\begin{array}{l}85 \\
65\end{array}$ & $\begin{array}{l}35 \pm<1 \\
18 \pm<1\end{array}$ & $\begin{array}{l}35 \\
29\end{array}$ & $\begin{array}{l}36 \\
35\end{array}$ \\
\hline $\begin{array}{l}50 \text { mg DDS, } \\
3 \times \text { per week }\end{array}$ & $2-6$ & 75 & 87 & $37 \pm 1$ & 23 & 27 \\
\hline $\begin{array}{l}50 \mathrm{mg} \text { DDS } \\
5 \times \text { per week }\end{array}$ & $2-021$ & 70 & 86 & $25 \pm 1$ & 27 & 34 \\
\hline
\end{tabular}

* Values are from plasma collected at $6 \mathrm{~h}$ and urine collected during 0-6 h following an oral dose of $10 \mathrm{mg} \mathrm{SMZ} \mathrm{per} \mathrm{kg}$.

† Mean value from levels of DDS and MADDS in plasma at 4, 6, 8, 24 and $48 \mathrm{~h}$.

$\ddagger T_{\frac{1}{2}}$ values were calculated from regression equations of levels of DDS and MADDS at 8, 24 and $48 \mathrm{~h}$ unless otherwise noted; $r$ values $\geqslant-0.95$.

$\S T_{\frac{1}{2}}$ values were based on plasma levels at $4,6,8$ and $24 \mathrm{~h}$. 
intermediate dosage group, and $60 \%$ of the high dosage group were rapid acetylators. The last two columns of Table 1 list the $T_{\frac{1}{2}}$ values for DDS and MADDS in these patients. No definitive relationships between dosage of DDS or percentage acetylation of DDS and these $T_{\frac{1}{2}}$ values were clearly indicated, although the 5 patients receiving the highest DDS dosage apparently exhibited, on the average, shorter $T_{\frac{1}{2}}$ values than the other groups.

The results of Study 2, which was more detailed than Study 1, are shown in Table 2. Again, patients are grouped by the DDS dosage and the patients that participated in both studies are indicated by employing the same patient numbers as those shown in Table 1. The percentage acetylation of SMZ in plasma and urine are shown in columns 3 and 4, respectively. From the acetylation of SMZ in plasma-the most discriminating test for acetylator phenotype (Peters et al., 1975)—we divided these patients into 9 rapid acetylators, i.e. those exhibiting a percentage of acetylation of SMZ ranging from 56 to $87 \%$; and 12 slow acetylators, i.e. those exhibiting a percentage of acetylation of SMZ ranging from 16 to $38 \%$. The acetylation of SMZ in urine and of DDS in plasma agreed with the assignment of acetylator phenotype for each patient. Also, the 5 patients of Study $2(1,8,7,16$ and 6$)$, who were also subjects of Study 1, were found to be the same phenotype as that suggested by the results of Study 1. Again, variability of the acetylation of DDS at the various times in individual patients of Study 2 was small (column 5) indicating that acetylation was stable during the time of this study. In the groups of patients receiving 50 and $75 \mathrm{mg}$ DDS per week, 33 and $38 \%$ were rapid acetylators, respectively. In the 4 patients receiving $\geqslant 100 \mathrm{mg}$ DDS per week, 3 (75\%) were rapid acetylators. Columns 6 and 7 of this table list the $T_{\frac{1}{2}}$ values of DDS and MADDS in these patients. Evaluations of these values will be subsequently discussed.

Table 3 summarizes the distribution of acetylator phenotypes in both Studies 1 and 2. Column 5 shows that the antimode of DDS acetylation assumed for patients of Study 1 was found to occur also in those of Study 2. Nevertheless, it is clear from the distribution of acetylation of SMZ in plasma (column 3) and in urine (column 4) that this drug is far superior to DDS for discriminating between acetylator phenotypes. The 5 patients of Study 2 (last

TABLE 3

Distribution of acetylator phenotypes in Studies 1 and 2

\begin{tabular}{llccc}
\hline \multirow{2}{*}{ Study* } & $\begin{array}{l}\text { Acetylator } \\
\text { phenotype* }\end{array}$ & SMZ, plasma & $\begin{array}{c}\text { Acetylation (mean, range) } \\
\text { SMZ, urine }\end{array}$ & DDS, plasma \\
\hline \multirow{2}{*}{$1(20)$} & Rapid (7) & - & - & $35,27-45$ \\
& Slow (13) & - & - & $16,13-23$ \\
$2(21)$ & Rapid (9) & $72,56-87$ & $88,85-94$ & $32,25-41$ \\
& Slow (12) & $28,16-38$ & $59,52-70$ & $15,10-21$ \\
$2(5)^{\dagger}$ & Rapid (3) & $78,71-87$ & $89,85-94$ & $38,35-41$ \\
& Slow (2) & $20,16-24$ & $52,52-53$ & $12,10-15$ \\
\hline
\end{tabular}

* The number of patients is shown in parenthesis.

$\dagger$ These 5 were subjects in both Studies 1 and 2 . 


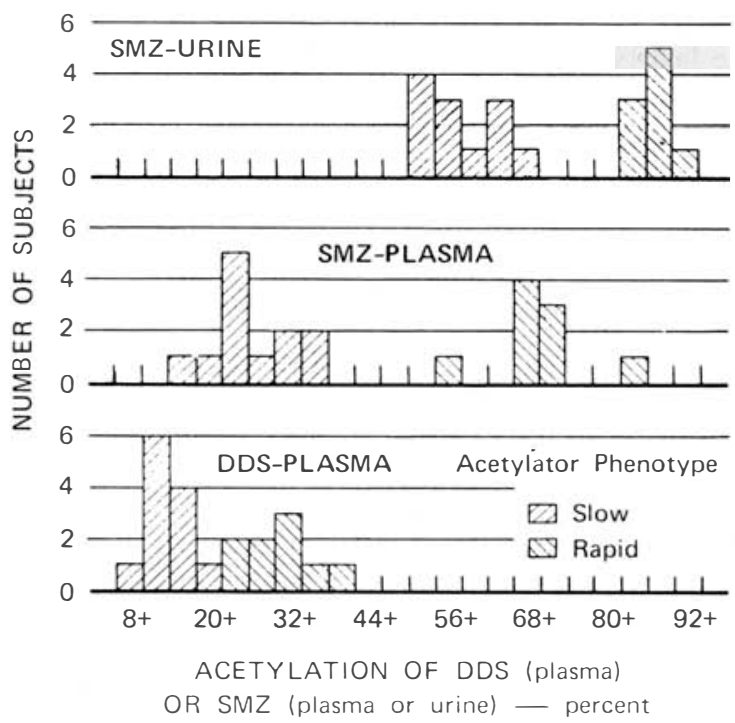

Fig. 1. Distribution of acetylator phenotypes of the patients of Study 2. On the abscissa each division represents a range of 3 percentage units, e.g. $8+=8-11 \%$.

line), who were participants in Study 1 also were more clearly phenotyped with SMZ than with DDS. This point is strikingly emphasized by Fig. 1, a plot of the distribution of acetylation capacities for SMZ and DDS of the patients of Study 2.

More detailed comparisons of the results in the 5 patients of both studies are shown in Table 4. Only patients 1 and 7 were on the same dosage schedule of DDS in the two studies. Significant differences $(P<0.001)$ in the mean percentage of acetylation in the two studies were noted in patients 1 and 6 , but not in the other 3 patients. However, these differences did not alter the classification of phenotype in patients 1 and 6 and therefore, within these limits, we can conclude that the acetylation capacity of the individuals was sufficiently stable with time to yield the same phenotype. Patient 7 , on the same dosage schedule, and patients 8 and 16, on different schedules, exhibited identical mean values in the two studies. These results indicate that acetylation capacity is relatively stable with time and is not influenced by the dosage schedules employed in these studies. Similarly, the $T_{\frac{1}{2}}$ values of DDS and MADDS in the two studies did not differ consistently or substantially, indicating also that these parameters were relatively stable and not influenced by the dosages of DDS employed.

The mean $( \pm$ S.E. $)$ age and body weight of the 21 patients in Study 2 were $38( \pm 2)$ years and $54( \pm 2) \mathrm{kg}$, respectively. The 8 female patients of the group had a mean age of $34( \pm 3)$ years and a mean body weight of $52( \pm 2) \mathrm{kg}$; the 13 male patients averaged $40( \pm 3)$ years and $55( \pm 2) \mathrm{kg}$. Neither the mean ages nor the body weights of the two sexes differed significantly. The group of 
TABLE 4

Comparison of results from 5 patients in Studies 1 and 2

\begin{tabular}{ccccccc}
\hline & \multicolumn{2}{c}{$\begin{array}{c}\text { Acetylation of DDS } \\
\text { Mean } \pm \text { S.E. }\end{array}$} & \multicolumn{2}{c}{$T_{\frac{1}{2}}$ of DDS (h) } & \multicolumn{2}{c}{$T_{\frac{1}{2}}$ of MADDS (h) } \\
$\begin{array}{c}\text { Patient } \\
\text { number* }\end{array}$ & Study 1 & Study 2 & Study 1 & Study 2 & Study 1 & Study 2 \\
\hline 1 & $19 \pm 2$ & $10 \pm<1$ & 24 & 18 & 28 & 20 \\
6 & $45 \pm 1$ & $37 \pm 1$ & 35 & 23 & 32 & 27 \\
7 & $42 \pm 2$ & $41 \pm 1$ & 27 & 24 & 32 & 27 \\
8 & $15 \pm<1$ & $15 \pm<1$ & 24 & 18 & 24 & 21 \\
16 & $34 \pm<1$ & $35 \pm<1$ & 30 & 35 & 32 & 36 \\
\hline
\end{tabular}

* The dosages of DDS administered were identical in Studies 1 and 2 for patients 1 and 7. Patient 6 received $25 \mathrm{mg}$ DDS, $3 \times$ per week, in Study 1 and $50 \mathrm{mg}$ DDS, $3 \times$ per week, in Study 2 . Patient 8 received $25 \mathrm{mg}$ DDS, $3 \times$ per week, in Study 1 and $25 \mathrm{mg}, 2 \times$ per week, in Study 2 . Patient 16 received $50 \mathrm{mg}$ DDS, $3 \times$ per week, in Study 1 and $50 \mathrm{mg}$ DDS, $2 \times$ per week, in Study 2 .

9 rapid acetylator phenotypes consisted of 3 female and 6 male patients; that of the slow characteristic comprised 5 female and 7 male patients. These distributions of sexes within phenotypes were judged to be random by the chisquare test (Goldstein, 1964). Finally, the average age ( $35 \pm 3$ years) and body weight $(53 \pm 3 \mathrm{~kg})$ of the 9 rapid acetylators did not differ significantly from the mean age $(40 \pm 3$ years) and body weight $(55 \pm 2 \mathrm{~kg})$ of the 12 slow acetylators. Thus, phenotype was not related to sex, age, or body weight.

Table 5 presents similar comparisons of $T_{\frac{1}{2}}$ values of DDS and MADDS for the entire group of patients of Study 2, for the sexes and acetylators, and for the various groups receiving different dosage schedules of DDS. None of the various sub-classes differed significantly from any other, indicating that the disappearance rates of DDS or MADDS were unrelated to any of these characteristics.

\section{TABLE 5}

Comparison of the $T_{\frac{1}{2}}$ values for DDS and MADDS in various groups of patients in Study 2

\begin{tabular}{|c|c|c|}
\hline \multirow[b]{2}{*}{ Group* } & \multicolumn{2}{|c|}{ Mean $( \pm$ S.E. $) T_{\frac{1}{2}}(\mathrm{~h})$} \\
\hline & DDS & MADDS \\
\hline All patients (21) & $28 \pm 1$ & $31 \pm 2$ \\
\hline Females (8) & $26 \pm 2$ & $26 \pm 2$ \\
\hline Males (13) & $30 \pm 2$ & $34 \pm 2$ \\
\hline Rapid acetylators (9) & $28 \pm 2$ & $31 \pm 2$ \\
\hline Slow acetylators (12) & $29 \pm 2$ & $31 \pm 2$ \\
\hline $\begin{array}{l}\text { Patients receiving } 25 \mathrm{mg} \text { DDS; } \\
2 \times \text { per week }(9)\end{array}$ & $26 \pm 2$ & $30 \pm 4$ \\
\hline $\begin{array}{l}\text { Patients receiving } 25 \mathrm{mg} \text { DDS; } \\
3 \times \text { per week }(8)\end{array}$ & $31 \pm 2$ & $31 \pm 2$ \\
\hline $\begin{array}{l}\text { Patients receiving } 50 \mathrm{mg} \text { DDS; } \\
2,3 \text {, or } 5 \times \text { per week }(4)\end{array}$ & $29 \pm 3$ & $33 \pm 2$ \\
\hline
\end{tabular}

* The number of patients in each group is shown in parenthesis. 
TABLE 6

Examination of various correlations of the data obtained from the patients of Study 2

\begin{tabular}{|c|c|c|c|}
\hline Correlation examined & $N$ & Correlation coefficient & $\begin{array}{l}\text { Significance of } \\
\text { confidence interval }\end{array}$ \\
\hline \multicolumn{4}{|l|}{$\%$ acetylation of $\mathrm{SMZ}$ in plasma versus: } \\
\hline$\%$ acetylation of SMZ in urine & 21 & 0.9378 & $<0.001$ \\
\hline plasma SMZ & 21 & -0.9270 & $<0.001$ \\
\hline plasma AcSMZ & 21 & 0.8166 & $<0.001$ \\
\hline \multicolumn{4}{|l|}{$\%$ acetylation of DDS versus: } \\
\hline$\%$ acetylation of SMZ in plasma & 21 & 0.9434 & $<0.001$ \\
\hline$\%$ acetylation of SMZ in urine & 21 & 0.9102 & $<0.001$ \\
\hline $\begin{array}{l}\text { dose-ad justed plasma DDS at } 4,6 \text {, } \\
8,24 \text { or } 48 \mathrm{~h} \text { in patients }\end{array}$ & & & \\
\hline receiving DDS $2 \times$ weekly & $11^{*}$ & -0.1876 to 0.5309 & N.S. \\
\hline $\begin{array}{l}\text { dose-ad justed plasma DDS at } 4,6 \text {, } \\
8,24 \text {, or } 48 \mathrm{~h} \text { in patients }\end{array}$ & & & \\
\hline receiving DDS $3 \times$ weekly & $9 \dagger$ & -0.5422 to -0.0090 & N.S. \\
\hline \multicolumn{4}{|l|}{$\begin{array}{l}\text { dose-ad justed plasma MADDS at } 4 \text {, } \\
6,8,24 \text {, or } 48 \mathrm{~h} \text { in patients }\end{array}$} \\
\hline receiving DDS $2 \times$ weekly & $11^{*}$ & 0.8988 to 0.9750 & $<0.001$ \\
\hline \multicolumn{4}{|l|}{$\begin{array}{l}\text { dose-ad justed plasma MADDS at } 4 \text {, } \\
6,8,24, \text { or } 48 \mathrm{~h} \text { in patients }\end{array}$} \\
\hline receiving DDS $3 \times$ weekly & $9+$ & 0.8736 to 0.9150 & $<0.005$ \\
\hline$T_{\frac{1}{2}}$ of DDS & 21 & -0.0841 & N.S. \\
\hline$T_{\frac{1}{2}}^{\frac{1}{2}}$ of MADDS & 21 & -0.0861 & N.S. \\
\hline $\mathrm{age}^{\frac{1}{2}}$ & 21 & -0.1930 & N.S. \\
\hline body weight & 21 & -0.2638 & N.S. \\
\hline \multicolumn{4}{|l|}{$T_{1}$ of DDS versus: } \\
\hline${ }^{\frac{1}{2}} T_{\frac{1}{2}}$ of MADDS & 21 & 0.7460 & $<0.001$ \\
\hline age & 21 & 0.1567 & N.S. \\
\hline body weight & 21 & 0.2594 & N.S. \\
\hline
\end{tabular}

* This group consisted of the 9 patients receiving $25 \mathrm{mg}$ DDS, $2 \times$ per week, and the 2 patients receiving $50 \mathrm{mg}$ DDS, $2 \times$ per week.

† This group consisted of the 8 patients receiving $25 \mathrm{mg}$ DDS, $3 \times$ per week, and the patient receiving $50 \mathrm{mg}, 3 \times$ per week. 
The results of examination of various correlations of the data of Study 2 by linear regression analysis are shown in Table 6 . The first three entries indicate that acetylation of SMZ in plasma and in urine were positively related and the variation of the percent acetylation in plasma was a result of decreased amounts of SMZ (negative correlation) and increased amounts of AcSMZ (positive correlation) in plasma. The next two entries indicate that, in individual patients, acetylation of DDS was directly related to acetylation of $\mathrm{SMZ}$ in both plasma and urine.

For the next evaluations, we calculated plasma levels of DDS and MADDS in units of $\mu \mathrm{g}$ of compound per mg of DDS per $\mathrm{kg}$ of body weight to correct for different dosages used and the different body weights of the subjects. Because the plasma samples were obtained after the last dose of DDS given during the week, we employed that dose of DDS for the different schedules to obtain these dose-adjusted values. Also, for brevity, and because the results of the correlation analyses for different times after administration were the same, we have presented evaluations of the dose-adjusted levels versus acetylation of DDS as ranges of the correlation coefficients (column 3). No significant correlation between percent acetylation of DDS and dose-adjusted levels of DDS in patients receiving 25 or $50 \mathrm{mg}$ DDS, two or three times per week was found. However, similar evaluations employing dose-adjusted levels of MADDS, as shown by the next two entries, were always directly related to the percentage acetylation of DDS. These evaluations indicate that the varying percentage acetylation of DDS resulted from varying amounts of MADDS in plasma, without concomitant changes in the amounts of DDS.

Subsequent entries show that the percentage acetylation of DDS in the individual patients was not related to the $T_{\frac{1}{2}}$ of DDS or of MADDS, or to the age or body weight of the subjects. However, the last group of entries clearly indicates that the $T_{\frac{1}{2}}$ of DDS and of MADDS were directly related but that the $T_{\frac{1}{2}}$ of DDS was unrelated to age or body weight of the patients.

${ }^{2}$ Finally, the different DDS regimens received by these patients allowed an evaluation of the influence of total dose during the week on the levels of DDS observed shortly after the final administration. The first sample collected from these patients, irrespective of the schedule, was at $4 \mathrm{~h}$. At this time, different $T_{\frac{1}{2}}$ values of DDS in the patients would tend to have minimal effect on the level observed. Figure 2 shows that the levels observed at $4 \mathrm{~h}$ were directly related to the total mg of DDS given per week and that the plasma levels at $4 \mathrm{~h}$ were elevated by approximately the same multiple as that used to increase the total dosage.

\section{Discussion}

As we discussed previously (Peters et al., 1975), assignment of acetylator phenotype on the basis of single tests with $\mathrm{SMZ}$ presumes that acetylation capacities of individuals are stable characteristics. Our current finding that the 5 patients of Studies 1 and 2 exhibited the same phenotype for the acetylation of DDS adds more evidence to that already accumulated for the stability in man of the acetylation characteristics for INH (Peters et al., 1965), SMZ (Peters et al., 1972), and DDS (Gelber et al., 1971). In addition, our 


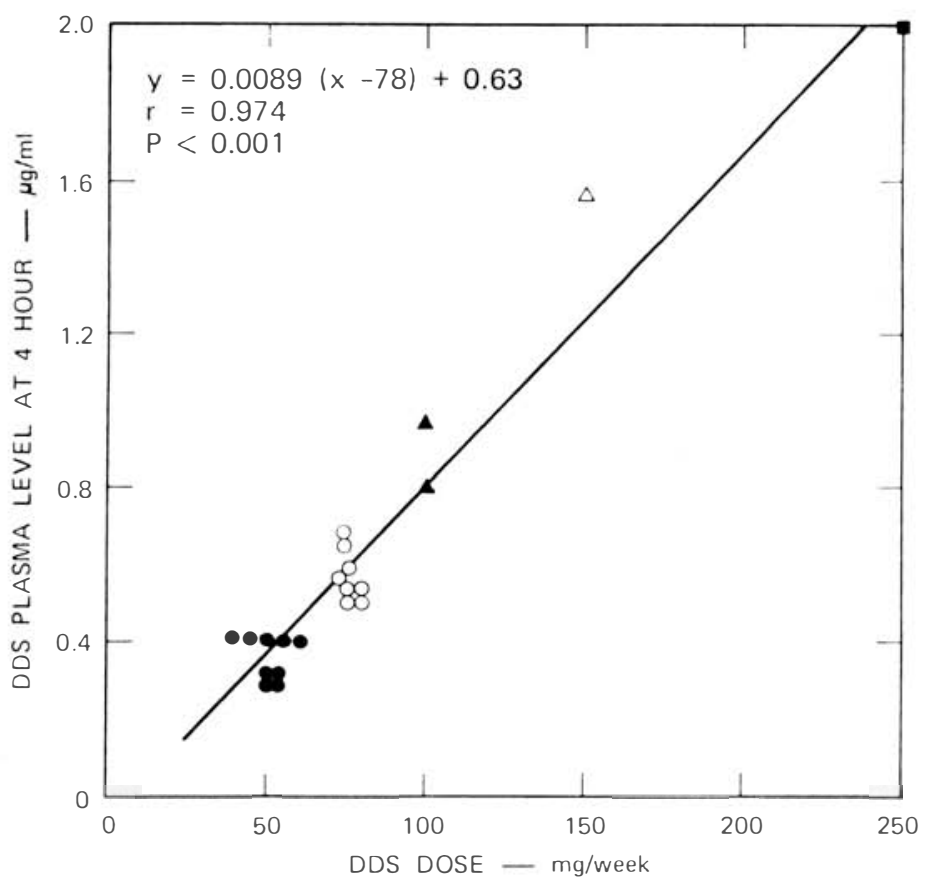

Fig. 2. Relationship between dosage of DDS (mg/week) and plasma levels of DDS at $4 \mathrm{~h}$ in the 21 patients of Study $2(\boldsymbol{O}=25 \mathrm{mg}, 2 \times$ per week; $O=25 \mathrm{mg}, 3 \times$ per week; $\boldsymbol{\Delta}=50 \mathrm{mg}, 2 \times$ per week; $\triangle=50 \mathrm{mg}, 3 \times$ per week; $\boldsymbol{\square}=50 \mathrm{mg}, 5 \times$ per week). The regression equation is in the form $y=b(x-\bar{x})+\bar{y}$ in which $b$ is the slope of the line and $\bar{x}$ and $\bar{y}$ are the mean values of $x$ and $y$.

observation of nearly the same $T_{\frac{1}{2}}$ values of DDS and MADDS in these 5 patients in Study 1, and 11 months later in Study 2, confirms similar results we obtained earlier in 6 Filipino subjects (Peters et al., 1972), and indicates that clearance rates of DDS and MADDS from the circulation are also stable individual characteristics even though unrelated to acetylator phenotype.

The clear parallel between the acetylation of DDS and SMZ in all the patients of the current studies adds this ethnic group to those previously studied in the United States (Gelber et al., 1971), the Philippines (Peters et al., 1972), South India (Peters et al., 1975), Costa Rica (Peters et al., 1976b), and New Guinea (Peters et al., 1977b), wherein acetylation of SMZ and DDS were found to be directly related. In addition, earlier reports of direct parallels among the acetylation of INH, SMZ, and DDS (Gelber et al., 1971) and between INH and SMZ (Evans et al., 1960; Evans and White, 1964) support the conclusion that the same genetic polymorphism for acetylation of all three of these drugs is operative in man. This fact is further supported by comparisons of proportions of the rapid phenotype in the current studies with those reported earlier in various Negro populations. In Studies 1 and 2, we found that 7 of 20 patients (35\%) and 9 of 21 patients $(43 \%)$ were rapid 
acetylators, respectively. These are quite similar to the frequency of the rapid phenotype for INH or SMZ of 47\% of 95 (Dufour et al., 1964) and 46\% of 31 (Mitchell et al., 1960) American Negroes; 35\% of 102 Sudanese (Evans, 1962); 45\% of 204 East African (Ellard et al., 1975); and 51\% of 109 Nigerian Negroes (Fawcett and Gammon, 1975).

Other aspects of the results found in the current studies are the same as those found earlier in other population groups (Gelber et al., 1971; Peters et al., 1972, 1975, 1976b, 1977b). These include a poorer definition of acetylator phenotype with DDS than with SMZ; the finding that DDS acetylation and levels of MADDS were directly related but that extent of acetylation was not related to levels of DDS; that age or body weight of the patients was unrelated to either acetylation of DDS or the $T_{\frac{1}{2}}$ value of DDS; and that $T_{\frac{1}{2}}$ values for DDS and MADDS were directly related. This last relationship reflects the stability of DDS acetylation with time.

Recently, Olson et al. (1978) reported that $T_{\frac{1}{2}}$ values of SMZ in man were dependent upon the dose of SMZ employed in têsts for acetylator phenotype. Thus, increasing single doses of SMZ from 5 to $40 \mathrm{mg} / \mathrm{kg}$ gave consistent increases in $T_{\frac{1}{2}}$ values, with the maximum increase being 3.5 -fold in one subject. Percentage acetylation was not consistently affected by dosage. In the current studies with DDS, we did not observe any consistent dose-effect on either percentage acetylation of DDS or $T_{\frac{1}{2}}$ of DDS in the 3 patients of both Studies 1 and 2 who received different weekly dosages of DDS (Table 4). In addition, no statistical differences in the $T_{\frac{1}{2}}$ values for DDS and MADDS were observed in the sub-groups of patients of Study 2 receiving various weekly doses of DDS (Table 5). Therefore, our observations do not suggest any doseeffect on the acetylation or clearance of DDS. Further support for this conclusion is derived from the linear relationship between the weekly dose of DDS and the level of DDS found $4 \mathrm{~h}$ following the last administration (Fig. 2).

In a study of DDS levels in whole blood of patients in Brazil, receiving 100 mg DDS daily, Beiguelman et al. (1974) concluded that variations of DDS levels in their patients were not related to the polymorphism of acetylation of DDS. These authors measured only DDS levels. We have emphasized repeatedly in our earliest (Gelber et al., 1971; Peters and Levy, 1971) and subsequent studies (Peters et al., 1972, 1975, 1976b, 1977b) that the polymorphism for the acetylation of DDS can only be detected by measurements of both DDS and its acetylated metabolite, MADDS, and that rapid and slow acetylators do not exhibit related variations in DDS levels. This conclusion is reinforced in the current studies by the lack of correlation between dose-adjusted DDS levels and percentage acetylation shown in Table 6. As in all previous work in other populations, this table shows that levels of MADDS were directly correlated with percentage acetylation and therefore determine the extent of acetylation of DDS. These aspects of DDS acetylation differ from the polymorphic acetylation of SMZ (Table 6) and INH (Peters et al., 1965) wherein parent drug levels are always negatively, and acetylated drug levels are always positively related with extents of acetylation. Thus, acetylator phenotype can be determined for INH and SMZ by simply measuring levels of the parent drug. This is not true for DDS. 
As recently emphasized by Ellard (1975), DDS clearly surpasses all other bacteriostatic drugs for antileprosy activity. Thus, peak plasma or serum concentrations of approximately 300 times the minimal inhibitory concentration (MIC) of DDS for M. leprae and maintenance of levels in excess of the MIC for about 10 days are achieved following a single dose of $50 \mathrm{mg}$ of DDS. Also, no tissue barriers to DDS are apparent from results of studies in rodents and man (Peters et al., 1976a). However, in patients receiving adequate DDS or DADDS chemotherapy no relationships between lack of response to chemotherapy and metabolic characteristics of poor responders could be discerned (Peters et al., 1977b). Furthermore, both earlier (Ellard et al., 1972) and more recent studies (Gelber and Rees, 1975; Peters et al., 1976b; Balakrishnan and Ramu, 1977) concluded that the occurrence of DDSresistance was not related to the metabolic characteristics of the resistant patients. Thus, none of the metabolic characteristics of patients receiving adequate monotherapy with DDS or DADDS have been shown to be responsible for poor response or relapse with DDS-resistant disease.

This may not be the case in patients receiving combination therapy because recent findings indicate that rifampin added to DDS regimens causes accelerated plasma clearance of DDS (Gelber and Rees, 1975) and dramatic decreases in the levels of DDS in plasma, skin, and radial nerve (Peters et al., $1977 a, 1978)$. Whether or not these decreases in DDS levels will have an adverse effect on therapeutic response has not been determined. Interactions between DDS and other drugs used for leprosy chemotherapy have not been studied.

\section{References}

Balakrishnan, S. and Ramu (1977). Blood DDS levels and acetylation rates of sulphadimidine in leprosy patients. Lepr. India 49, 59.

Beiguelman, B., Pinto, W., Jr, El-Guindy, M. M. and Krieger, H. (1974). Bull. Wld Hlth Org. $51,3291$.

Dufour, A. P., Knight, R. A. and Harris, H. W. (1964). Genetics of isoniazid metabolism in Caucasian, Negro and J apanese populations. Science 145, 391.

Ellard, G. A. (1975). Pharmacological aspects of the chemotherapy of leprosy. Lepr. Rev. 46 (Suppl.), 41.

Ellard, G. A., Gammon, P. T., Rees, R. J. W. and Waters, M. F. R. (1971). Studies on the determination of the minimal inhibitory concentration of 4,4'-diamino-diphenyl-sulf one (dapsone, DDS) against Mycobacterium leprae. Lepr. Rev. 42, 101.

Ellard, G. A., Gammon, P. T., Helmy, H. S. and Rees, R.J. W. (1972). Dapsone acetylation and the treatment of leprosy. Nature $239,159$.

Ellard, G. A., Gammon, P. T. and Tiitinen, H. (1975). Determination of the acetylator phenotype using matrix isoniazid. Tubercle 56, 203.

Evans, D. A. P. (1962). Pharmacogenetique. Med. Hyg. 20, 905.

Evans, D. A. P. and White, T. A. (1964). Human acetylation polymorphism. J. Lab. clin. Med. 63, 394.

Evans, D. A. P., Manley, K. A. and McKusick, V. A. (1960). Genetic control of isoniazid metabolism in man. Br. med.J. 2, 485.

Fawcett, I. W. and Gammon, P. T. (1975). Determination of the acetylator phenotype in a Northern Nigerian population. Tubercle 56, 199.

Gelber, R. H. and Rees, R. J. W. (1975). Dapsone metabolism in patients with dapsone-resistant leprosy. Am. J.trop.Med. Hyg. 24, 963. 
Gelber, R., Peters, J. H., Gordon, G. R., Glazko, A. J. and Levy, L. (1971). The polymorphic acetylation of dapsone in man. Clin. Pharmac. Ther. 12, 225.

Goldstein, A. (1964). Biostatistics. Macmillan, New York.

Gordon, G. R., Ghoul, D. C. and Peters, J. H. (1975). Identification and quantitation of impurities in dapsone preparations. J. Pharm. Sci.64, 1205.

Mitchell, R. S., Bell, J. C. and Riemensnider, D. K. (1960). Further observations with isoniazid inactivation tests. Transactions of the 19th Conference on Chemotherapy of Tuberculosis, p. 62.

Murray, J. F., Jr, Gordon, G. R. and Peters, J. H. (1971). A chromatographic-fluorometric procedure for the determination of nanogram quantities of antileprotic sulfones. J. Lab. clin. Med. 78, 464.

Olson, W., Miceli, J. and Weber, W. (1978). Dose-dependent changes in sulfamethazine kinetics in rapid and slow acetylators. Clin. Pharmac. Ther. 23, 204.

Peters, J. H. (1972). Polymorphic acetylation of dapsone in man. 5th International Congress on Pharmacology, San Francisco, CA, July 23-28, 1972. Abstracts, p. 181.

Peters, J. H. and Levy, L. (1971). Dapsone acetylation in man: another example of polymorphic acetylation. Ann. N.Y. Acad. Sci. 179, 660.

Peters, J. H., Miller, K. S. and Brown, P. (1965). Studies on the metabolic basis for the genetically-determined capacities for isoniazid inactivation in man. J. Pharmac. exp. Ther. 150, 298.

Peters, J. H., Gordon, G. R. and Colwell, W. T., Jr (1970). The fluorometric measurement of $4,4^{\prime}$-diaminodiphenyl sulf one and its acetylated derivatives in plasma and urine. J. Lab. clin. Med. 76, 338.

Peters, J. H., Gordon, G. R., Ghoul, D. C., Tolentino, J. H., Walsh, G. P. and Levy, L. (1972). The disposition of the antileprotic drug dapsone (DDS) in Philippine subjects. Am. J. trop. Med. Hyg. 21, 450.

Peters, J. H., Gordon, G. R. and Karat, A. B. A. (1975). Polymorphic acetylation of the antibacterials, sulfamethazine and dapsone, in South Indian subjects. Am. J. trop. Med. Hyg. 24, 641.

Peters, J. H., Murray, J. F., Jr, Gordon, G. R., Gelber, R. H., Levy, L., Laing, A. B. G. and Waters, M. F. R. (1976a). Tissue levels of dapsone in mice, rats, and man. Int.J. Lepr. 44, 545.

Peters, J. H., Shepard, C. C., Gordon, G. R., Rojas, V., A. and Elizondo S., D. (1976b). The incidence of DDS resistance in lepromatous patients in Costa Rica; their metabolic disposition of DDS. Int. J. Lepr. 44, 143.

Peters, J. H., Murray, J. F., Jr, Gordon, G. R., Gelber, R. H., Laing, A. B. G. and W aters, M. F. R. (1977a). Effect of rif ampin on the disposition of dapsone in Malaysian leprosy patients. Fedn Proc. 36, 996.

Peters, J. H., Murray, J. F., Jr, Gordon, G. R., Levy, L., Russell, D. A., Scott, G. C., Vincin, D. R. and Shepard, C. C. (1977b). Acedapsone treatment of leprosy patients: response versus drug disposition. Am.J.trop. Med. Hyg. 26, 127.

Peters, J. H., Murray, J. F., Jr, Gordon, G. R. and Jacobson, R. R. (1978). Metabolicbacteriologic relationships in the chemotherapy of lepromatous patients with dapsone and dapsone-rif ampin. Int. J. Lepr. 46, 115.

Russell, D. A., Shepard, C. C., McRae, D. H., Scott, G. C. and Vincin, D. R. (1975). Acedapsone (DADDS) treatment of leprosy patients in the Karimui of Papua New Guinea: status at six years. Am.J. trop. Med. Hyg. 24, 485.

Sansarricq, H. (1977). Recent advances and trends in leprosy research. Experientia 33, 114. 